\title{
Evaluation of Simplified Leaf Inoculation Procedures for Identification of Quantitative Resistance to Sclerotinia trifoliorum in Alfalfa Seedlings
}

\author{
R. G. Pratt and D. E. Rowe, USDA-ARS, Waste Management \& Forage Research Unit, P.O. Box 5367, \\ Mississippi State, MS 39762
}

\begin{abstract}
Pratt, R. G., and Rowe, D. E. 1998. Evaluation of simplified leaf inoculation procedures for identification of quantitative resistance to Sclerotinia trifoliorum in alfalfa seedlings. Plant Dis. 82:1161-1164.

Previous studies established that excised leaf tissues of alfalfa can be inoculated with Sclerotinia trifoliorum to select for heritable resistance, but the original procedures were not practical for use in large-scale screening programs. In this study, simplified leaf inoculation procedures for more rapid screening for resistance, based on direct application of leaf tissues to colonies of the pathogen on agar media, were evaluated. Cotyledons, unifoliate leaves, and leaflets of trifoliolate leaves of plants 7 to 21 days old from three relatively susceptible cultivars and one resistant germ plasm were applied, with and without wounding, directly to colony margins of S. trifoliorum on cornmeal agar, V8 juice agar, and water agar. Leaves were scored according to the rate and extent of development of necrosis. Significant differences between alfalfa populations were expressed in unifoliate leaves and trifoliolate leaflets but not in cotyledons. Disease severity in the resistant germ plasm (Mississippi Sclerotinia-Resistant [MSR]) was less than in the three cultivars on all agar media. Wounding of leaf tissues increased disease severity and greatly reduced the incidence of symptomless leaves, which are indicated to be escapes, but wounding generally did not prevent expression of resistance in MSR. Results indicate that initial screening for resistance to $S$. trifoliorum in alfalfa seedlings may be accomplished by applying wounded unifoliate leaves and leaflets of trifoliolate leaves directly to colonies on cornmeal or V8 juice agars.
\end{abstract}

Sclerotinia crown and stem rot, caused by Sclerotinia trifoliorum Eriks., is a major disease of alfalfa and other forage legumes in the southeastern and south-central United States, where these crops are fallplanted. Until very recently, control could be attained only through use of certain cultural practices such as deep plowing (8), early planting (10), and foliar clipping (3). These practices are often inconvenient or expensive to apply, and consequently the disease has been largely uncontrolled.

Rapid advances in development of host plant resistance to $S$. trifoliorum in alfalfa have been made in recent years, and it is expected that resistant cultivars will become available in the near future. To date, one resistant germ plasm (Mississippi Sclerotinia-resistant [MSR]) (7) and one resistant cultivar (WL 332 SR) (1) have been released. These advances have been

Mention of a trademark or proprietary product does not constitute an endorsement or warranty of the product by the U.S. Department of Agriculture and does not imply its approval to the exclusion of other products that may also be suitable.

Accepted for publication 14 July 1998.

Publication no. D-1998-0803-02R

This article is in the public domain and not copyrightable. It may be freely reprinted with customary crediting of the source. The American Phytopathological Society, 1998. made partly through the use of new techniques that enable more reliable identification of resistance in individual plants by repeated assays of host tissues. Inoculations of excised stems and leaves were shown to be effective in selecting for heritable resistance to $S$. trifoliorum that was further expressed with whole-plant inoculations under controlled conditions and with natural infection in the field $(4,5,7)$. It is anticipated that use of these and other (2) screening procedures will lead to widespread development and use of resistant cultivars in future years.

The previously described leaf inoculation techniques (4) were more efficient than stem inoculations and enabled screening for resistance in unifoliate leaves of very young plants. However, they are still time-consuming and labor-intensive because they require harvesting of leaf tissue from plants, cutting of disks from trifoliolate leaves, placement of leaves or disks on agar, cutting of inoculum disks from colonies, and placement of inoculum disks onto leaves or disks (4). Therefore, although these original techniques are effective, they are not fully satisfactory for use in screening programs where large numbers of plants must be inoculated in a short time.

The MSR germ plasm, developed largely by screening for resistance with leaf inoculation techniques, is known to possess heritable resistance to $S$. trifo- liorum that is expressed in excised leaf tissue, with whole-plant inoculations, and with natural infection in the field (7). Therefore, this germ plasm provides an excellent resistant control for development of improved screening procedures. Any laboratory or greenhouse procedures that reveal the relative resistance of MSR, in comparison to predominantly susceptible cultivars (6), should be potentially useful in screening for resistance.

Techniques in which excised leaf tissues could be applied directly to colony margins of $S$. trifoliorum on agar media for evaluation of host resistance would be more efficient than original inoculation procedures (4). Therefore, this study was undertaken to evaluate the expression of resistance to S. trifoliorum in alfalfa when cotyledons, unifoliate leaves, and trifoliate leaflets are applied directly to colonies grown on different agar media with and without wounding of leaf tissue.

\section{MATERIALS AND METHODS}

Storage and growth of $S$. trifoliorum. Sclerotia of a moderately virulent isolate of $S$. trifoliorum from alfalfa (isolate 1 in citation 6) were stored air-dried for up to a year at $10^{\circ} \mathrm{C}$ prior to use. To initiate mycelial growth, sclerotia were surface-disinfested in sodium hypochlorite, rinsed, bisected, and plated on agar $(4,6)$. Transfers were made after 4 to 5 days from growing colony margins to plates of V8 juice agar (V8A) (20\% V8 juice, 2\% agar) and incubated at $5^{\circ} \mathrm{C}$. Subsequent transfers, with continued incubation at $5^{\circ} \mathrm{C}$, were made only from growing colony margins to new plates at weekly intervals before colonies reached the plate edge. For inoculum production, S. trifoliorum was transferred from colony margins to centers of plates and grown for 2.5 days on V8A, 3 days on Difco cornmeal agar (CMA), and 4 days on $2 \%$ water agar (WA) at $25^{\circ} \mathrm{C}$ prior to placement of leaf tissue on plates.

Growth of plants and collection and inoculation of leaf tissue. Seeds of alfalfa cultivars Apollo, Cimarron, and Delta, and of a germ plasm (MSR) with a high level of quantitative resistance to $S$. trifoliorum (7), were germinated on inverted plates of WA to obtain plants of uniform age, planted by hand into plastic cones with a greenhouse potting mixture, dusted with inoculum of Rhizobium meliloti, and grown in a greenhouse (4). Single cotyledons were excised from plants at 7 days by 
cutting with a scalpel across the stalk adjacent to the growing point. Unifoliate leaves were excised at the tip of the petiole at 10 days after planting, and terminal leaflets of trifoliolate leaves were excised after 3 weeks. Cotyledons and unifoliate leaves were inverted and placed on plates with distal lateral edges appressed to the agar within 1 to $2 \mathrm{~mm}$ of growing colony margins. Trifoliolate leaflets were placed on plates in the same manner but not inverted. For wounding treatments, a small incision was made with a scalpel or razor blade through each cotyledon or leaf from the distal lateral edge to approximately $2 \mathrm{~mm}$ inward at the point closest to the colony margin.
Eight cotyledons, unifoliate leaves, or trifoliolate leaflets were placed around the colony margin of $S$. trifoliorum on each plate. Plates were randomized in blocks on a bench under plant growth lights (80 $\mu \mathrm{E} \cdot \mathrm{m}^{-2} \cdot \mathrm{s}^{-1}$ intensity) at $17^{\circ} \mathrm{C}$ as previously described $(4,6)$. Each block contained a single replicate plate of each treatment. Leaves were observed daily, and numerical scores of 1 to 7 were assigned inversely according to the day after inoculation when leaves became completely necrotic (4), e.g., leaves that first became completely necrotic at 2 and 6 days after inoculation were scored 6 and 2, respectively. A leaf not completely necrotic at 7 days was

Table 1. Sources of variation and their significance for scores of symptom severity in individual or combined experiments with cotyledons, unifoliate leaves, and leaflets of trifoliolate leaves of alfalfa plants from four populations added to colonies of Sclerotinia trifoliorum on agar media with and without wounding

\begin{tabular}{llrcc}
\hline $\begin{array}{l}\text { Plant tissue } \\
\text { (experiment) }\end{array}$ & Source of variation & df & Mean square & P > F \\
\hline Cotyledons & Alfalfa population & 3 & 0.44 & $\mathrm{NS}^{\mathbf{z}}$ \\
(Single expt.) & Agar media & 2 & 257.46 & $<0.01$ \\
& Wound & 1 & 7.82 & $<0.05$ \\
& Population $\times$ media & 6 & 0.41 & $\mathrm{NS}$ \\
& Population $\times$ wound & 3 & 0.10 & $\mathrm{NS}$ \\
& Wound $\times$ media & 2 & 0.83 & $\mathrm{NS}$ \\
& Population $\times$ wound $\times$ media & 6 & 0.30 & $\mathrm{NS}$ \\
& Error & 69 & 0.31 & \\
Unifoliate leaves & Alfalfa population & 3 & 10.74 & $<0.01$ \\
(combined expts.) & Agar media & 2 & 189.07 & $<0.01$ \\
& Wound & 1 & 138.81 & $<0.01$ \\
& Population $\times$ media & 6 & 0.29 & $\mathrm{NS}$ \\
& Population $\times$ wound & 3 & 0.11 & $\mathrm{NS}$ \\
& Wound $\times$ media & 2 & 12.20 & $<0.01$ \\
& Population $\times$ wound $\times$ media & 6 & 1.40 & $<0.01$ \\
& Error & 141 & 0.49 & \\
Trifoliolate leaflets & Alfalfa population & 3 & 16.66 & $<0.01$ \\
$($ Combined expts.) & Agar media & 2 & 29.15 & $<0.01$ \\
& Wound & 1 & 152.75 & $<0.01$ \\
& Population $\times$ media & 6 & 0.23 & $\mathrm{NS}$ \\
& Population $\times$ wound & 3 & 2.61 & $<0.05$ \\
& Wound $\times$ media & 2 & 10.32 & $<0.01$ \\
& Population $\times$ wound $\times$ media & 6 & 0.47 & NS \\
& Error & 141 & 0.35 & \\
\hline
\end{tabular}

${ }^{y}$ Level of probability for a greater value of $F$.

${ }^{\mathrm{z}}$ Not significant.

scored 0.00 to 0.99 by a visual estimate of the percentage of tissue that was necrotic (4). The mean score for the eight cotyledons, unifoliate leaves, or leaflets in each plate was used as the experimental unit.

Experimental design and statistical analysis. Each experiment with cotyledons, unifoliate leaves, and trifoliolate leaflets was a $4 \times 3 \times 2$ factorial (four alfalfa populations $\times$ three agar media $\times$ two wounding treatments), with four replicate plates of each treatment arranged in a randomized complete block design. Each experiment was performed twice with different groups of plants. Analysis of variance (ANOVA) was performed by SAS procedures (9), and results of repeated experiments were combined when heterogeneity of variance was not significant $(P=0.05)$. Means were separated by use of Duncan's new multiple range test at $P=0.05$.

\section{RESULTS}

Scores for symptom severity. Sources of variation for scores of symptom development in leaf tissues are given in Table 1. Significant differences between alfalfa populations occurred in both experiments with unifoliate leaves and trifoliolate leaflets, but in only one experiment with cotyledons (data not presented). Significant differences also were attributed to agar media and wound treatments for all types of plant tissue. Significant interactions occurred between wound treatments and agar media in all experiments with unifoliate leaves and trifoliolate leaflets, and between alfalfa populations and wound treatments with trifoliolate leaflets (Table 1).

Mean scores of disease severity for the four alfalfa populations in unifoliate leaves and trifoliolate leaflets are given in Table 2. In unifoliate leaves in the absence of wounding, MSR had significantly $(P=$ 0.05 ) lower disease scores than all three cultivars on CMA and V8A, but not on WA. With wounding of unifoliate leaves,

Table 2. Mean scores of disease severity in excised unifoliate leaves and leaflets of trifoliolate leaves of alfalfa plants from four populations added to colonies of Sclerotinia trifoliorum on agar media with and without wounding ${ }^{\mathrm{x}}$

\begin{tabular}{|c|c|c|c|c|c|c|c|}
\hline \multirow{3}{*}{$\begin{array}{l}\text { Leaf } \\
\text { tissue }\end{array}$} & \multirow{3}{*}{$\begin{array}{l}\text { Alfalfa } \\
\text { population }\end{array}$} & \multicolumn{6}{|c|}{ Agar media and wounding $(0 /+)^{y}$} \\
\hline & & \multicolumn{2}{|c|}{ CMA } & \multicolumn{2}{|c|}{ V8A } & \multicolumn{2}{|c|}{ WA } \\
\hline & & $\mathbf{0}$ & + & $\mathbf{0}$ & + & $\mathbf{0}$ & + \\
\hline \multirow[t]{4}{*}{ Unifoliate leaf } & Apollo & $4.51 \mathrm{a}^{\mathrm{z}}$ & $5.20 \mathrm{a}$ & $3.12 \mathrm{a}$ & $5.04 \mathrm{a}$ & $0.23 \mathrm{a}$ & $2.69 \mathrm{a}$ \\
\hline & Cimarron & $4.32 \mathrm{a}$ & $5.12 \mathrm{ab}$ & $3.58 \mathrm{a}$ & $5.07 \mathrm{a}$ & $0.37 \mathrm{a}$ & $2.42 \mathrm{a}$ \\
\hline & Delta & $4.43 \mathrm{a}$ & $4.83 \mathrm{bc}$ & $2.59 \mathrm{a}$ & $5.25 \mathrm{a}$ & $0.53 \mathrm{a}$ & $2.19 \mathrm{a}$ \\
\hline & MSR & $3.30 \mathrm{~b}$ & $4.56 \mathrm{c}$ & $1.21 \mathrm{~b}$ & $4.23 \mathrm{~b}$ & $0.13 \mathrm{a}$ & $1.13 \mathrm{~b}$ \\
\hline \multirow[t]{4}{*}{ Trifoliolate leaflet } & Apollo & $2.69 \mathrm{a}$ & $4.01 \mathrm{a}$ & $3.75 \mathrm{a}$ & $4.48 \mathrm{a}$ & $0.95 \mathrm{a}$ & $3.81 \mathrm{a}$ \\
\hline & Cimarron & $2.19 \mathrm{a}$ & $3.96 \mathrm{a}$ & $2.37 \mathrm{bc}$ & $4.43 \mathrm{a}$ & $0.78 \mathrm{a}$ & $3.73 \mathrm{a}$ \\
\hline & Delta & $2.67 \mathrm{a}$ & $3.53 \mathrm{a}$ & $2.69 \mathrm{~b}$ & $4.23 \mathrm{a}$ & $0.38 \mathrm{a}$ & $3.54 \mathrm{a}$ \\
\hline & MSR & $1.79 \mathrm{a}$ & $2.20 \mathrm{~b}$ & $1.61 \mathrm{c}$ & $3.05 \mathrm{~b}$ & $0.31 \mathrm{a}$ & $2.13 \mathrm{~b}$ \\
\hline
\end{tabular}

${ }^{x}$ Leaves and leaflets were excised from plants, placed on agar at margins of colonies of S. trifoliorum (eight per plate), and scored for disease severity within 1 week. Values are means for eight plates from two experiments. Each plate was an experimental unit with a value equal to the mean score for eight leaves or leaflets.

y $\mathrm{CMA}=$ cornmeal agar, V8A = V8 juice agar, WA = water agar. + wound = a slash made with a scalpel through the distal-lateral edge of leaf or leaflet, extending 1 to $2 \mathrm{~mm}$ deep into tissue, adjacent to colony margin of S. trifoliorum. MSR = Mississippi Sclerotinia-resistant.

${ }^{\mathrm{z}}$ Mean scores for disease severity, where $0.00=$ least severe and $7.00=$ most severe. Within leaf-tissue groups, means within columns followed by the same letter do not differ significantly at $P=0.05$ according to Duncan's new multiple range test. 
MSR differed significantly from all three cultivars on V8A and WA, but not on CMA. In trifoliolate leaflets, MSR differed significantly $(P=0.05)$ from all three cultivars on all media with wounding, but not on any medium without it. Disease scores did not differ significantly among the three cultivars on most media, with or without wounding (Table 2).

Occurrence of symptomless leaves. Sources of variation for the occurrence of symptomless tissues ( 0 values in scoring system) in combined experiments with unifoliate leaves and trifoliolate leaflets are given in Table 3. No significant differences in occurrence of 0 values were attributed to alfalfa populations for either unifoliate leaves or trifoliolate leaflets. Highly significant differences in occurrence of 0 values were attributed to agar media, wound treatments, and to media by wound interactions for both types of plant tissue.

Mean numbers of 0 values for unifoliate leaves and trifoliolate leaflets on the different agar media, with and without wounding, are given in Table 4. Values are not given for the four alfalfa populations because these did not differ significantly. For both unifoliate leaves and trifoliolate leaflets, the occurrence of 0 values was significantly $(P=0.05)$ reduced by wounding on all agar media and almost eliminated on CMA and V8A.

\section{DISCUSSION}

Results of this study demonstrate that excised leaf tissues of alfalfa may be added directly to colonies of $S$. trifoliorum on agar media to identify host resistance. Since the MSR germ plasm is known to possess quantitative resistance that is effective in excised leaf tissues, with wholeplant inoculations, and with natural infection in the field, as well as against numerous isolates of S. trifoliorum and S. sclerotiorum (7), then any conditions that reveal the relative resistance of MSR potentially could be used in screening for resistance. In this study, the relative resistance of MSR, compared with three more susceptible cultivars, was expressed in unifoliate leaves and trifoliolate leaflets on all agar media either with or without wounding of tissue. Therefore, these tissues and conditions potentially are suitable for use in screening for resistance. With cotyledons, in contrast, no consistent significant differences in disease scores were attributed to main effects or interactions of alfalfa populations. This indicates either that the relative resistance of MSR is not expressed in cotyledons, or that the experimental conditions of this study were not adequate to enable its expression consistently.

A second criterion for use of a leaf inoculation technique as a procedure to screen for resistance is that relatively few symptomless plants can be tolerated. If the absence of symptoms in excised leaf tissue were an indication of host resistance, then this would be a favorable characteristic to be sought in screening. However, results of this study revealed no differences in the occurrence of zero values between alfalfa populations for either unifoliate leaves or trifoliate leaflets (Table 3). This indicates that zero values were randomly distributed among all populations, and therefore, that symptomless leaves represent escapes rather than highly resistant host genotypes. Relatively high frequencies of symptomless tissues occurred without wounding in unifoliate leaves and trifoliolate leaflets on all media. Wounding of tissues greatly decreased these frequencies.

Results suggest that for screening for resistance to $S$. trifoliorum with relatively few escape plants, wounded unifoliate leaves can be placed directly on colonies of S. trifoliorum on CMA or V8A for initial selection of resistant phenotypes. On CMA, however, the resistance of MSR was not expressed, in comparison to all three cultivars with wounding of unifoliates.

The most susceptible appearing genotypes can be discarded on the basis of unifoliate leaf responses, and remaining plants then can be evaluated repeatedly for resistance in leaflets of trifoliolate leaves. Wounded trifoliolate leaflets can be placed directly on colony margins of S. trifoliorum on CMA or V8A, as with unifoliate leaves, for further screening. Under these conditions, the incidence of symptomless escape plants should be negligible. Use of known resistant and susceptible populations as controls in such screening experiments would be desirable to ascertain that differences in quantitative resistance are expressed.

It was recommended previously that a moderately virulent isolate of $S$. trifoliorum be used in screening for resistance, to avoid overwhelming the relatively low levels of resistance that are present initially in most alfalfa populations (4). The experimental conditions and conclusions of this study also are based on use of such an isolate. If more virulent isolates (6) are used in screening, then further modifications may be necessary to ensure optimal expression of host resistance.

Adding unifoliate leaves and trifoliolate leaflets of alfalfa directly to colonies of $S$.

Table 3. Sources of variation and their significance for occurrence of symptomless tissues ( 0 values) in combined experiments with unifoliate leaves and trifoliolate leaflets of alfalfa plants from four populations added to colonies of Sclerotinia trifoliorum on agar media with and without wounding

\begin{tabular}{lllcc}
\hline Plant tissue & Source of variation & df & Mean square & $\boldsymbol{P}>\boldsymbol{F}^{\mathbf{y}}$ \\
\hline Unifoliate & Alfalfa population & 3 & 1.84 & $\mathrm{NS}^{\mathrm{z}}$ \\
leaves & Agar media & 2 & 259.57 & $<0.01$ \\
& Wound & 1 & 325.52 & $<0.01$ \\
& Population $\times$ media & 6 & 0.52 & $\mathrm{NS}$ \\
& Population $\times$ wound & 3 & 0.76 & $\mathrm{NS}$ \\
& Wound $\times$ media & 2 & 75.79 & $<0.01$ \\
& Population $\times$ wound $\times$ media & 6 & 1.42 & $\mathrm{NS}$ \\
Trifoliolate & Error & 141 & 1.14 & \\
leaflets & Alfalfa population & 3 & 0.93 & $\mathrm{NS}$ \\
& Agar media & 2 & 149.76 & $<0.01$ \\
& Wound & 1 & 336.02 & $<0.01$ \\
& Population $\times$ media & 6 & 1.60 & $\mathrm{NS}$ \\
& Population $\times$ wound & 3 & 0.28 & $\mathrm{NS}$ \\
& Wound $\times$ media & 2 & 99.32 & $<0.01$ \\
& Population $\times$ wound $\times$ media & 6 & 0.58 & $\mathrm{NS}$ \\
& Error & 141 & 0.77 & \\
\hline
\end{tabular}

${ }^{y}$ Level of probability for a greater value of $F$.

z Not significant.

Table 4. Occurrence of symptomless tissues ( 0 values) across alfalfa populations in combined experiments with unifoliate leaves and trifoliolate leaflets added to colonies of Sclerotinia trifoliorum on agar media with and without wounding ${ }^{\mathrm{w}}$

\begin{tabular}{lcccc}
\hline & & \multicolumn{3}{c}{ Agar media $^{\mathbf{x}}$} \\
\cline { 4 - 5 } Leaf tissue & Wounding $^{\mathbf{y}}$ & CMA & V8A & WA \\
\hline Unifoliate leaf & 0 & $1.06 \mathrm{a}^{\mathrm{z}}$ & $1.69 \mathrm{a}$ & $6.72 \mathrm{a}$ \\
& + & $0.00 \mathrm{~b}$ & $0.03 \mathrm{~b}$ & $1.62 \mathrm{~b}$ \\
Trifoliolate leaflet & 0 & $1.00 \mathrm{a}$ & $1.44 \mathrm{a}$ & $6.03 \mathrm{a}$ \\
& + & $0.06 \mathrm{~b}$ & $0.00 \mathrm{~b}$ & $0.53 \mathrm{~b}$ \\
\hline
\end{tabular}

${ }^{\mathrm{w}}$ Leaves and leaflets were excised from plants, placed on agar at margins of colonies of S. trifoliorum (eight per plate), and scored for disease severity within 1 week. Values are mean numbers of symptomless plant tissues ( 0 values) for eight plates from two experiments. Each plate was an experimental unit with eight leaves or leaflets.

${ }^{x} \mathrm{CMA}=$ cornmeal agar, V8A $=$ V8 juice agar, $\mathrm{WA}=$ water agar.

$\mathrm{y}+$ wound $=\mathrm{a}$ slash made with a scalpel through the distal-lateral edge of leaf or leaflet, extending 1 to $2 \mathrm{~mm}$ deep into tissue, adjacent to colony margin of $S$. trifoliorum.

${ }^{\mathrm{z}}$ Within leaf-tissue groups, means within columns followed by the same letter do not differ significantly at $P=0.05$ according to Duncan's new multiple range test. 
trifoliorum on agar media should enable more rapid screening for resistance in large populations than was possible with original leaf inoculation procedures (4). These simplified procedures also should be investigated for use with clovers and other hosts after possible modifications for specieslevel differences in resistance and susceptibility.

\section{LITERATURE CITED}

1. Anonymous. 1996. W-L Introduces WL 332 SR. The Haymaker. (Summer):1. W-L Research, Evansville, WI.

2. Pierson, P. E., St. Martin, S. K., and Rhodes, L. H. 1994. Greenhouse selection for resis- tance to Sclerotinia crown and stem rot in alfalfa. Proc. Am. Forage Council, 50th. 1994:312-315.

3. Pratt, R. G. 1991. Evaluation of foliar clipping treatments for cultural control of Sclerotinia crown and stem rot in crimson clover. Plant Dis. 75:59-62.

4. Pratt, R. G. 1996. Screening for resistance to Sclerotinia trifoliorum in alfalfa by inoculation of excised leaf tissue. Phytopathology 86:923-928.

5. Pratt, R. G., and Rowe, D. E. 1994. Responses to selection for resistance to Sclerotinia trifoliorum in alfalfa by stem inoculations. Plant Dis. 78:826-829.

6. Pratt, R. G., and Rowe, D. E. 1995. Comparative pathogenicity of isolates of Sclerotinia trifoliorum and S. sclerotiorum on alfalfa cul- tivars. Plant Dis. 79:474-477.

7. Pratt, R. G., and Rowe, D. E. 1996. Registration of Mississippi Sclerotinia-Resistant (MSR) alfalfa germplasm. Crop Sci. 36:821822.

8. Rhodes, L. H., and Gilbert, R. G. 1990 Sclerotinia crown and stem rot. Pages 26-28 in: Compendium of Alfalfa Diseases. 2nd ed. D. L. Stuteville and D. C. Erwin, eds. American Phytopathological Society, St Paul, MN.

9. SAS Institute. 1991. SAS Procedures for Linear Models. 3rd ed. SAS Institute, Cary, NC.

10. Sulc, R. M., and Rhodes, L. H. 1997. Planting date, fungicide, and cultivar effects on Sclerotinia crown and stem rot severity in alfalfa. Plant Dis. 81:13-17. 